\title{
YATIRIM PROJELERI ANALIZINDE BLACK-SCHOLES OPSIYON FIYATLAMA MODELININ KULLANIMI
}

\author{
Yrd. Doç. Dr. Erkan Uysal \\ Ankara Üniversitesi \\ Siyasal Bilgiler Fakültesi
}

\section{Ōzet}

Bu çalş̧mada, finansal opsiyon fiyatlama modellerinin yatınm projelerinin değerlendirilmesinde kullanım incelenmektedir. Özellikle, belirsizlik ve riskin yüksek olduğu projelerde, gelencksel indirgenmiş nakit akımı (INA) yaklaşımu zayıf sonuçlar vermektedir. Böyle yatırımlarda belirsizliğgi dikkate alan reel opsiyon yaklaşımı etkin biçimde kullanılabilmektedir. Bir finansal opsiyon ile bir yatırım projesi arasındaki benzerlikler incelenerek, bir alım opsiyonu olarak ifade edilen yatum projesinin ekonomik değeri Black-Scholes opsiyon fiyatlama modeli çerçevesinde hesaplanmışur. Son olarak, hesaplanan proje değerinin iskonto oranı ve risklilikteki değişmelerden ne yönde ve ne ölçüde etkileneceği duyarlılık analizi yardımı ile incelenmiştir.

\section{Using Black-Scholes Option Pricing Model in Investment Project Appraisal}

\section{Abstract}

In this paper, I studied the application of the financial option pricing model in project appraisal. The traditional discounted cash flow (DCF) technique underestimates the value of a project that has high uncertainty and risk. As an alternative, the real option value approach can be used to enhance the results of the traditional DCF technique. By examining the similarities between an investment project and a financial option, an investment project can be defined as a call option. Furthermore, the Black-Scholes option pricing model can be used in valuing the investment project that is defined as a call option. Finally, the possible effects of changes in discount rate and risk level on project value are analyzed by applying sensitivity analysis. 


\section{Yatırum Projeleri Analizinde Black-Scholes Opsiyon Fiyatlama Modelinin Kullanımı}

\section{Giriş}

Firmalar yatırım kararlarını değerlendirirken pekçok faktörü dikkate alır. Yatırım kararlarının amacı, firmanun piyasa değerini artırmak ve değişen koşullara uyum sağlamaktır. Hatta, sabit sermaye yatıımlanını işletmelerin varlıkların devam ettirebilmelerinin temel nedeni olduğu söylenebilir (SARIASLAN, 1997: 24). Firmalar yatırımlar sözkonusu olduğunda çeşitli seçeneklerle karşı karşıya kalırlar. Bu seçenckler, birden fazla yatırım alternatifi olduğunda, bu alternatifler arasında kıt kaynakları en optimal biçimde dağıtmak için yatırımlardan hangisinin veya hangilerinin seçileceğine ilişkin olabileceği gibi, tek bir yatnnm projesi sözkonusu olduğunda da, bu projenin hayata geçirilip geçirilmeyeceğine ilişkin olabilir. Yatırımı gerçekleştirip gerçekleştirmeme tamamı ile firmanın insiyatifine bağlıdır. Bu insiyatif nedeni ile yatırım fırsatları birer opsiyon olarak değerlendirilebilir. Yatınm projelerinin değerlendirilmesinde opsiyon yaklaşımı, özellikle belirsizlik ve riskin yüksek olduğu ortamlarda, diğer geleneksel proje değerlendirme yaklaşımlarına göre daha doğru sonuçlar vermektedir.

Reel opsiyonların en çok karşılaşıldığı projeler ARGE projeleridir. Firmalar ARGE projeleri için büyük miktarda fonlar ayırdıklan için, bu fonların en doğru biçimde değerlendirilmesi firmalar için büyük önem taşır. Bir araştırma ve geliştirme projesi başladığında, projeye ilişkin nakit akımlarını belirlemek oldukça zordur. Çünkü, proje yöneticileri hem araştırma sonuçlarına ilişkin teknik belirsizlikle, hem de sonuçta elde edilecek ürünün talebine ilişkin piyasa belirsizliği ile karşı karşıyadır. Ancak, ARGE projelerindeki belirsizlik zaman ile azalır. Çünkü, proje ilerledikçe yeni bilgiler elde edilir ve alınan kararlar bu yeni bilgiler ışığında yeniden gözden geçirilerek gerekli düzeltmeler yapilur.

ARGE projeleri aşamalı projelerdir ve farklı aşamalarda farklı riskler (belirsizlikler) barındırır. Bunun yanında, bu projeler yüksek belirsizlik içerir ve 
yatırılan kaynakların getirisi çok ileri dönemlerde ortaya çkar. Bu projelerin . yüksek belirsizlik içermesi ekonomik değerlendirmenin zorlaşmasına neden olmaktadır. Ilk olarak Myers, ARGE projelerinin ekonomik değerinin gelecekteki fırsatlardan dolayı bir opsiyon değeri barındırdıklann ve bu tür opsiyon barındıran projelerin değerlendirilmesinde geleneksel INA yöntemlerinden daha farklı yöntemlerin kullanımına ihtiyaç olduğunu vurgulamıştır (MYERS, 1984: 128). Kester, ARGE projelerini birbirleri ile karşılaştırmıs ve bunların değer yaratan yeni yatırım fursatların gerçekleştirmeyi sağlayan opsiyonlara sahip oldukların ortaya koymuştur (KESTER, 1984: 159). Morris, Teisberg ve Kolbe, aynı NBD'e sahip ancak farklı belirsizlik ve risk seviyelerindeki ARGE projelerini analiz etmişler geleneksel yaklaşımlar ile reel opsiyon yaklaşımının farklı sonuçlar verdiğini göstermişlerdir (MORRIS vd, 1991 aktaran HEMANTHA/CHAN, 1999: 1).

Reel opsiyon literatüründeki son gelişmeler, finansal opsiyonlanı fiyatlama teorisinin reel opsiyonları değerlendirmede de kullanulabileceğini göstermiştir (KROLL, 1998: 22). Özellikle, yatırım projesi hisse senedi sahiplerinin varlığın maksimizasyonu çerçevesinde NBD hesaplamaları ile değerlendirildiğinde ve bilgi clde edilebilirliğinde ex-ante ve ex-post farklılıklar olması durumunda reel opsiyonların kullanımının standart NBD yöntemini zenginleştirdiği görülmüştür. Ex-ante ve ex-post bilgi elde edilebilirliği arasında fark olması, yatırım projesi verilerine ilişkin açık bir belirsizliği ifade eder. Bu durumda, geçen süre belirsizliğin çözümüne önemli bir katkı yapabilir. Bugün yapılan bir yatırım (ARGE yatımları, yeni bir pazarlama programı veya sermaye harcamaları) ileri dönemlerde yeni ürün veya yeni pazar firsatların yaratabilir (BRIGHAM/GAPENSKI, 1994: 442). Bu tür yatrımlan değerlendirirken gelencksel indirgenmiş nakit akımı analizleri, belirsizliği ele almadaki yetersizliklerinden dolayı yanış sonuçlara neden olabilir (DIXIT/PINDYCK, 1994: 26). Bu nedenle, reel opsiyon yaklaşımı proje değerlendirmede son yıllarda artan oranda kullanılmaktadır.

\section{Bir Reel Opsiyon Olarak Yatırım Projesi}

Öncelikle, opsiyon kavramın biraz açalım. Opsiyonlar, sahiplerine önceden belirlenmiş bir fiyat üzerinden birşeyleri alma veya satma hakkın (zorunluluğunu değil) veren hukuki sözleşmelerdir (FRANCIS, 1991: 675). Opsiyonlar Avrupa tipi opsiyon ve Amerikan tipi opsiyon olmak üzere ikiye ayrılır. Avrupa tipi opsiyonlar sadece vadesi geldiği zaman işleme konulabilir. Oysaki, Amerikan tipi opsiyonlar vadesine kadar herhangi bir zamanda işleme konulabilir (LEVI, 1996: 85).

Yatırım projeleri firmalar için zorunluluk gerektirmeyen, yapulıp yapılmayacağı firmanın insiyatifinde olan projelerdir. Yatırım projesinde, alım 
opsiyonunda olduğu gibi firma, bir zorunluluk olmadan bir aktifi elde etme hakkına sahiptir. Burada yatırımdan elde edilecek aktifler, ileri dönemlerdeki nakit girişleridir. Bu aktifi elde etmek için bir bedel ödemek gerekir. Bu bedel yatırımın gerektirdiği nakit çıkı̧landır. Benzer biçimde, bir alım opsiyonunda opsiyonun sağladığı fırsatı değerlendirebilmek için işlem fiyatı kadar bir ödeme yaparak, bunun karşılığında daha fazla bir nakit girişi elde edebiliriz. Bir opsiyonun değeri, bu opsiyonun sağlayacağı fırsatların ekonomik değeri ile orantılıdır. Eğer, opsiyon out-of-money durumunda ise, yani işlem fiyatı piyasa fiyatından yüksek ise, herhangi bir fırsat sözkonusu değildir. Çünkü, opsiyonun işleme konulması zarar ile sonuçlanacaktır. Opsiyon in-the-money durumunda ise, yani işlem fiyat piyasa fiyatından daha düşük ise önümüzde bir fırsat vardır. İşlem fiyatı kadar bir bedel ödeyerek elde edilen aktifi, bundan daha büyük miktarda bir karşlıkla piyasada satarak ek nakit girişi sağlayabiliriz. Bir opsiyon ile bir yatırım projesinin bu benzerliklerini Tablo-1'deki gibi ortak değişkenler aracılı̆ğ ile gösterebiliriz (LUEHRMAN, 1998: 52).

Tablo-1 Yatırım Projesi ve Hisse Senedi Opsiyonunun Karşılaşırılması

\begin{tabular}{|l|c|l|}
\hline Yatınm fırsatı & Değişken & Alım opsiyonu \\
\hline $\begin{array}{l}\text { Projeden elde edilecek (nakit } \\
\text { akımlarının) aktiflerin } \\
\text { bugünkü değeri }\end{array}$ & $\mathbf{P}$ & Hisse senedi fiyatı \\
\hline $\begin{array}{l}\text { Proje aktiflerini elde etmek } \\
\text { için gereken harcama }\end{array}$ & $\mathbf{X}$ & Işlem fiyatı \\
\hline $\begin{array}{l}\text { Yatırım kararlarının ertelene- } \\
\text { bileceği zaman dilimi }\end{array}$ & $\mathbf{t}$ & $\begin{array}{l}\text { Opsiyonun işlem tarihine } \\
\text { kalan zaman }\end{array}$ \\
\hline Paranın zaman değeri & $\mathbf{R}_{\mathrm{f}}$ & Risksiz getiri oranı \\
\hline Proje aktiflerinin riskliliği & $\sigma^{2}$ & $\begin{array}{l}\text { Hisse senedi getirilerinin } \\
\text { varyansı }\end{array}$ \\
\hline
\end{tabular}

Bir opsiyonun fiyat, hisse senedinin bugünkü fiyatına, vade tarihinde opsiyonun işlem fiyatna, vadeye kadar olan süreye, risksiz getiri oranuna ve hisse senedi değerindeki dalgalanmaya bağlıdır. Diğer yandan, bir yatırım projesinin değeri, projeden elde edilecek aktiflerin (nakit girişlerinin) bugünkü değerine, bu aktifleri elde etmek için gereken harcama tutarına, bu harcama tutarımn ödenmesinin ertelenebileceği süreye, paranın zaman değerine ve projeden elde edilecek aktiflerin riskliliğine bağhıdır. 
Yatırım projesinin başlangıৎ yatırımı, ileride elde edilecek nakit girişleri karşılığında ödenen bedeldir. tleride elde edilecek nakit akımları bir fırsatı temsil eder ve bu firsatı elde etmek için harcanması gerekli tutar bir alım opsiyonunun işlem fiyatına $(X)$ karşilık gelir. Benzer biçimde, projeden elde edilecek aktiflerin bugünkü değeri, hisse senedinin piyasa fiyatına eşittir. Firmanın, önündeki fırsatı kaybetmeden yatırımı erteleyebileceği zaman süresi opsiyonun vadesine(t), projenin gelecekteki nakit akımlarına ilişkin belirsizlik (projenin riskliliği) hisse senedi getirilerinin standart sapmasına $(\sigma)$ ve son olarak, paranın zaman değeri her ikisinde de risksiz getiri oranına $\left(R_{f}\right)$ karşıllık gelmektedir.

Geleneksel INA yaklaşımı, yatırım fưsatını bu yatırıma ilişkin nakit akımlarının net bugünkü değerini hesaplayarak değerlendirir. NBD yöntemine göre, projenin değeri ileri dönemlerde elde edilecek olan faaliyet aktiflerinin bugünkü değeri ile bu aktifleri elde etmek için harcadığımız miktarın bugünkü değeri arasındaki farka eşittir. Yani;

NBD = aktiflerin bugünkü değeri-gerekli sermaye harcamasının bugünkü değeri

NBD pozitif ise, elde edilecek aktiflerin değeri, bu aktifleri elde etmek için ödenen bedelden daha fazladır ve bu yatırımın yapılması firma değerini yükseltecektir. NBD negatif ise, yani, elde edilen aktifler ödenen bedelden daha az ise, firma bu yatırımı yapmayacaktır. Çünkü, NBD'si negatif olan bir projenin gerçekleştirilmesi firma değerini düşürecektir. Ileri dönemlerdeki aktifleri elde etmek için ödenecek bedelin ertelenmesi sözkonusu değil ise, yani $t=0$ ise, projenin NBD'si ve opsiyon değeri birbirine eşittir. Çünkü, opsiyonun fiyatı ve dolayısı ile sağlayacağı fayda bellidir. Opsiyonun vadesi geldiğinde, opsiyonun değeri hisse senedinin o andaki fiyatı $(P)$ ile işlem fiyatı $(X)$ arasındaki farka eşittir. Eğer, bu fark negatif ise $(P-X<0)$, yani elde edilecek aktiflerin değeri ödenecek bedelden düşük ise, opsiyon işleme konulmayacaktır ve opsiyonun değeri sıfır (0) olacaktur. Yani, opsiyonun fiyatı, P-X veya 0 'dan hangisi büyükse o olacaktır. Benzer şekilde, projenin net bugünkü değeri de P-X olacaktır. Projeden elde edilecek aktiflerin bugünkü değeri, bu aktifleri elde etmek için harcanacak miktarın bugünkü değerinden daha küçük ise NBD negatif $(P-X<0)$ olacaktır. Bu durumda yatırım fırsatının değeri sıfırdır ve projeye yatırım yapılmayacak, yani opsiyon işleme konulmayacaktır. Her iki yaklaşım da ayn sonuca ulaşır.

Ancak, yatırım karan fursatı elden kaçrmadan bir süre crtelenebiliyor ise, NBD ve reel opsiyon yaklaşımları farklı sonuçlara ulaşacaktır. Bunun başlıca iki nedeni vardır. Birincisi, ceteris paribus, her zaman için harcamaları geciktirmek daha avantajlıdır. Çünkü, harcanacak miktar üzerinden paranın zaman değerine göre bir miktar getiri elde edebiliriz. Ikincisi, bu bekleme süresinde içinde bulunulan şartlarda değişmeler olabilir. Şartların değişmesi sonucu elde 
edilecek aktiflerin bugünkü değerleri de değişebilir. Eğer bu aktiflerin değeri artarsa, bizim açımızdan kaybedilen birşey yoktur, yatrımı yapabiliriz. Aksi durumda, yani şartlar aleyhte gelişip te, elde dilecek aktiflerin değeri düşerse, karanımızı gözden geçirerek yatırım projesini tekrar inceleyebiliriz. Bekleyerek kötüye dönüşecek bir durumdan kurtulmuş oluruz ve bekleme sayesinde iyi sonuçlardan faydalanma ve kötü sonuçlardan da kaçınma avantajını elde ederiz. Bunlardan dolayı, beklemenin ekonomik bir değeri vardır. Geleneksel NBD yaklaşımı bu bekleme değerini gözardı etmektedir. Bu yaklaşıma göre, bir projenin gerçek değeri geleneksel NBD ile opsiyon değerinin toplamına eşittir (BRIGHAM, 1994: 443).

Gerçek NBD = Geleneksel NBD + Opsiyonun değeri

Burada, geleneksel NBD nakit akımların iskonto oranı üzerinden indirgeyerek kolayca bulunabilir. Ancak opsiyonun değerini hesaplamak biraz daha karışıktır.

\section{Black-Scholes Opsiyon Fiyatlama Modeli}

Opsiyon değerini hesaplamak için geliştirilen yöntemlerden en tanınmışı Fisher Black ve Myron Scholes tarafından, hisse senedinin sürekli getiri oranlarmın normal dağılıma sahip olduğu varsayımına dayalı olarak matematiksel formüllerden türetilen modeldir (FRANCIS, 1991: 690). Bu modelin temel eşitlikleri ve değişkenleri aşağıdaki gibidir.

$$
V_{0}=P N\left(d_{1}\right)-\frac{X}{e^{r_{f t}}} N\left(d_{2}\right)
$$

Bu formüldeki $d_{1}$ ve $d_{2}$ aşağıdaki gibi hesaplanır.

$$
d_{1}=\frac{\ln (\mathrm{P} / \mathrm{X})+\left(\mathrm{R}_{\mathrm{f}}+\sigma^{2} / 2\right) \mathrm{t}}{\sqrt[\sigma]{\mathrm{t}}}
$$

ve

$$
\mathrm{d}_{2}=\mathrm{d}_{1}-\sqrt[\sigma]{t}
$$

\section{Burada;}

$\mathrm{V}=$ opsiyonun bugünkü değerini,

$P=$ hisse senedinin bugünkü değerini,

$X=$ opsiyonun işlem fiyatıu, 
$\mathrm{e}=2.71828($ doğal logaritma $)$

$t=$ opsiyonun vadesine kadar süreyi,

$\mathrm{R}_{\mathrm{f}}=$ sürekli bileşik risksiz getiri oranın,

$\sigma=$ hisse senedi sürekli bileşik yıllık getirilerinin standart sapmasın,

$\ln (P / X)=(P / X)$ 'in doğal logaritmasını,

$N(d)=$ standart normal bir dağılımda $(0,1)$ d'den daha az bir sapmanın olma olasılı̆̆ını temsil etmektedir.

Hisse senedi getirilerinin normal dağılıma sahip olduğu varsayımına dayanarak türetilen bu formüller kullanılarak, risk altunda bir opsiyonun değeri hesaplanabilir. Şimdi, reel opsiyon yaklaşımını bir yatırım projesine uyarlayarak yatırım projesinin değerini bulalım.

\section{Opsiyon Fiyatlama Modelinin Yatırım Projesine Uygulanması}

Uygulama örneği için büyüme opsiyonu barındıran bir projeyi (örneğin bir ARGE projesi) ele alalım. Bu tür projelerde genellikle belli bir başlangıৎ̧ yatırımı vardır. Daha sonraki bir dönemde de büyüme amaa ile yapılacak olan büyük bir nakit çıkısı daha (sermaye harcaması) görülür. Tablo-2'de bir yatırım projesine ait nakit akımları verilmiştir. Projenin ömrü 10 yil olup, nakit akımlarının indirgenmesinde riske göre düzeltilmiş olan \%15'lik bir iskonto oran kullanılmaktadır.

Tablo- 2 Projenin Nakil Akımları Genel Durumu

\begin{tabular}{|c|c|c|c|c|c|c|c|c|c|c|c|}
\hline Yillar & 0 & 1 & 2 & 3 & 4 & 5 & 6 & 7 & 8 & 9 & 10 \\
\hline Net Nakit A kımı & & 50 & 61 & 76 & 90 & 108 & 410 & 475 & 580 & 650 & 840 \\
\hline Hurda Değeri & & & & & & & & & & & 1250 \\
\hline Yatırım Tutarı & -370 & & & & & -2250 & & & & & \\
\hline İskonto Faktörü & 1,00 & 0,87 & 0,76 & 0,66 & 0,57 & 0,50 & 0,43 & 0,38 & 0,33 & 0,28 & 0,25 \\
\hline Bugünkü Değer & -370 & 43,5 & 46,1 & 50,0 & 51,5 & $-1065,0$ & 177,3 & 178,6 & 189,6 & 184,8 & 516,6 \\
\hline
\end{tabular}

Örneğimizde, başlangıçta 370 birim nakit çıkışı (ilk yaturım) gerekmektedir. Yaplan bu yatırım karşıllı̆ında 10 yll boyunca nakit girişi sağlanacaktır. Bu nakit girişlerine ek olarak 5. yılda firmanın önünde bir firsat vardır. Bu fırsat, ek bir yatırım ile projenin nakit girişlerini artırmaktır. Ancak bu fırsatı değerlendirip değerlendirmemek firmanın insiyatifindedir. Yapılması planlanan bu ek yatưım sonucunda, başlangı̣ yatırımından sağlanan nakit 
girişlerine ek olarak yeni nakit girişleri elde edilecektir. Yani, projeyi iki aşamalı bir proje gibi düşünebiliriz. Ilk aşama başlangıçta yatırnlan tutar karş̧liğı elde edilen nakit akımları, ikinci aşama da 5. yıl yapılan ek yatrım sonucunda elde edilen ek nakit akımlarından oluşacaktır. Yatırımın ekonomik ömrü sonunda 1250 birimlik bir hurda veya tasfiye değeri vardır. Burada, yatırım projesinin ikinci aşamasın, belli bir aktifi (ileride sağlanacak nakit girişlerinin bugünkü değeri) elde etmek için işleme koyacağımız bir alım opsiyonu gibi düşünebiliriz. Çünkü ikino aşama firmanun önündeki bir firsattur ve bunu değerlendirmek tamamen keyfiyete bağıdır. Bu durumda projenin değerlendirmesini ikiye ayırmak gerekir.

NBD (toplam proje) $=$ NBD (birinci aşama $)+$ alım opsiyonu değeri (ikinci aşama)

Birinci aşama başlangıç yatırımını ve buna ilişkin nakit akımlarını, ikinci aşama ise büyüme fırsatını ifade etmektedir. Bu firsatı değerlendirmek zorunlu değildir ve değerlendirme kararı şartlara göre verilecektir. Projenin değerini doğru olarak saptayabilmek için ikinci aşamayı iyi analiz etmek gereklidir. Opsiyon açısından, sözkonusu aktifin değeri (P), opsiyonun işleme konulması halinde elde edilecek olan aktiflerin bugünkü değeridir. Opsiyonun işlem fiyat (X) ikinci aşamadaki aktifleri elde edebilmek için gerekli harcama tutarına (yatırım miktarı) eşittir. INA tablosuna göre opsiyonun vadesi 5 yıldır. Risksiz faiz oranı \%7 ve nakit akımlarını indirgemede kullanılan riske göre düzeltilmiş iskonto oranı $\% 15$ tir. Ayrica, aktiflerin getirilerinin standart sapmasınun da $\% 40$ olduğunu varsayalım. Burada sadece projenin riskliliği varsayıma dayalı olarak alınmıştır. Bir projeye ilişkin riskin analizi ve ölçümü, projenin ekonomik ömrünü kapsayan belirsizliklere ilişkin bilgiler gerektirdiği için oldukça güç bir iştir (SARIASLAN, 1997, 230). Bu nedenle, bu aşamada bu değiskeni varsayıma dayalı olarak ele alacağız.

Yapılması gereken ilk iş, projenin birinci ve ikinci aşamalarına ait nakit akımlarını ayrı ayrı belirlemektir. Cünkü, bu sayede ikinci aşamanı marjinal etkilerini analiz edebiliriz. Bu ayrımı yapmak zor bir iş değildir. Yatırım projesi hazırlanurken her nakit akımının kaynağı ve miktarı detaylı olarak bellidir.

Tablo-3'te ve Tablo-4'te yaturım projesinin aşamalarına göre detaylandırılmış nakit akımlan verilmiştir. $\mathrm{Bu}$ tablolardaki rakamlar toplandığında projenin genel nakit akımlarının verildiği Tablo-2'deki rakamlar elde edilecektir. 
Tablo- 3 Projenin 1. Aşamasına llişkin Nakil Akımlan

\section{Aşama}

Iskonto Oranı \% 15

\begin{tabular}{lrrrrrrrrrrr}
\hline \multicolumn{1}{c}{ Yıllar } & $\mathbf{0}$ & $\mathbf{1}$ & $\mathbf{2}$ & $\mathbf{3}$ & $\mathbf{4}$ & $\mathbf{5}$ & $\mathbf{6}$ & $\mathbf{7}$ & $\mathbf{8}$ & $\mathbf{9}$ & $\mathbf{1 0}$ \\
\hline \hline $\begin{array}{l}\text { Net Nakit Akımı } \\
\text { Hurda Değeri }\end{array}$ & & 50 & 61 & 76 & 90 & 108 & 125 & 160 & 185 & 210 & 240 \\
Yatırım Tutarı & -370 & & & & & & & & & & 275 \\
Iskonto Faktörü & 1,00 & 0,87 & 0,76 & 0,66 & 0,57 & 0,50 & 0,43 & 0,38 & 0,33 & 0,28 & 0,25 \\
Bugünkü Değer & -370 & 43,48 & 46,12 & 49,97 & 51,46 & 53,70 & 54,04 & 60,15 & 60,48 & 59,70 & 127,3 \\
\hline
\end{tabular}

Tablo-3'te, başlangıçta yapılan 370 birimlik yatırım karşılığl 10 yll boyunca elde edilecek nakit akımlan ve yatırımın hurda veya tasfiye değeri verilmiştir. Bu nakit akımları \%15'lik riske göre düzeltilmiş iskonto oranından indirgendiğinde projenin 1. aşamasının NBD'si 236.4 birim olarak bulunur. Yani; 5. yıldaki ek yatırım yapılmadan da INA yaklaşımına göre proje kabul edilebilir bir projedir.

Tablo- 4 Projenin 2. Aşamasına iliş̧kin Nakil Akımları

2. Aşama

\begin{tabular}{|c|c|c|c|c|c|c|c|c|c|c|c|}
\hline skonto Oranı & 15 & & & & & & & & & & \\
\hline Yillar & 0 & 1 & 2 & 3 & 4 & 5 & 6 & 7 & 8 & 9 & 10 \\
\hline Net Nakit Akım & & & & & & & 285 & 315 & 395 & 440 & 600 \\
\hline Hurda Değeri & & & & & & & & & & & 975 \\
\hline Yatırım Tutarı & & & & & & -2250 & & & & & \\
\hline Iskonto Faktörü & 1,00 & 0,87 & 0,76 & 0,66 & 0,57 & 0,50 & 0,43 & 0,38 & 0,33 & 0,28 & 0,25 \\
\hline Bugünkü Değer & & & & & & $-1118,6$ & 123,2 & 118,4 & 129,1 & 125,1 & 389,3 \\
\hline
\end{tabular}

Tablo-4'teki verileri kullanarak, INA yaklaşımına göre projenin ikinci aşamasının NBD'sini hesaplayabiliriz. 1. aşamada olduğu gibi riske göre düzeltilmiş \%15'lik iskonto oranını kullanarak nakit akımlarını indirgediğimizde projenin 2. aşamasının NBD'sini -233.5 birim olarak buluruz. Projenin 2. aşamasının NBD'si negatiftir ve bu aşamayı gerçckleştirmek firma değerini olumsuz yönde etkileyecektir.

INA yaklaşımını kullanarak benzer biçimde Tablo-2'de verilen değerleri \%15'lik iskonto oranın kullanarak indirgediğimizde projenin NBD'sini 2.9 birim olarak buluruz. Bu rakam ayn zamanda 1. ve 2 . aşamada bulduğumuz değerlerin toplamına eşittir. (236.4 birim $+-233.5=2.9$ birim)

Opsiyon yaklaşımına göre projenin toplam NBD'si en az 236.4 birim 
olmalıdır. Çünkü, opsiyonel bir fırsat olan ikinci aşamanın toplam proje değerine katkısı ya sıfır ya da pozitif bir değer olmalıdır. Bizim nakit akım tablomuza göre, ikinci aşamanın NBD'si -233.5 birimdir. A.slında burada, 5. yılın başındaki opsiyonel yatırımı indirgemede kullanılan iskonto oranından dolayı bir hata vardır. Bu hata, 5. yldaki yatrım tutannin da projenin nakit akımlarına uygulanan \%15 üzerinden iskonto edilmesinden kaynaklanmaktadır. Bu oran başlangıç yatırım tutarını indirgemede kullanmak için çok yüksektir. Çünkü, yatırım tutanı geçen süre içinde değerlendirebileceğimiz oran projenin iskonto oranundan daha düşük olmalıdır. Aksi takdirde, eğer elimizdeki paraya projenin sağladığ1 getiri oranı kadar getiri sağlayabiliyor isek, o takdirde elimizdeki kaynakları yaturım yapmak için kullanmaya hiç gerek yoktur . Bu nedenle, bu miktarı risksiz getiri oranı üzerinden iskonto etmek daha doğru olacaktır. Yaturım tutarınun olması gerekenden yüksek bir oranla indirgenmesi projenin NBD'sini olumlu biçimde etkileyecektir. Eğer, 5. yılın başındaki yatırım tutarın risksiz getiri oran (\%7) üzerinden indirgersek (diğer nakit akımları \%15 üzerinden indirgenecektir), projenin ikinci aşamasınun NBD'si -719.1 birim olacaktır. Bu durumda, projenin genel NBD'si de daha da düşecek ve -482.7 birim olacaktır.

Yukarıda INA yaklaşımına göre yapılan hesaplamalar 2. aşamanın reddedilmesi gerektiğini göstermektedir. Şimdi Tablo-1'de gösterilen ilişkiler çerçevesinde projenin ikinci aşamasın reel opsiyon yaklaşımına göre değerlendirelim. Opsiyon değerini hesaplayabilmek için değişkenlerin değerlerini saptamamız gerekmektedir. Bu durumda, $\mathrm{P}$ opsiyonun işleme konulması sonucu elde edilecek aktiflerin, yani nakit akımlanın net bugünkü değerine eşit olacaktır. 5. yıldan sonraki nakit akımlarının bugünkü değerleri toplamı 885.2 birim, opsiyonun işlem fiyatı olan yatırım tutarı 2250 birim, vadeye kadar olan süre 5 yll ve risksiz getiri oran $\% 7$ 'dir. Proje aktiflerinin riskliliğinin \%40 olduğunu varsayalım. Bu değişkenlerin değerlerini belirledikten sonra opsiyonun değerini hesaplayabiliriz.

$$
\begin{aligned}
& d_{1}=\frac{\ln (\mathrm{P} / \mathrm{X})+\left(\mathrm{R}_{\mathrm{f}}+\sigma^{2} / 2\right) \mathrm{t}}{\sqrt[\sigma]{\mathrm{t}}} \\
& d_{1}=\frac{\ln (885.2 / 2250)+(0.07+0.16 / 2) 5}{0.40 \sqrt{5}} \\
& d_{1}=-0.20452 \\
& \text { ve, } \\
& d_{2}=d_{1}-\sqrt[\sigma]{\mathrm{t}}
\end{aligned}
$$




$$
\begin{aligned}
& d_{2}=-0.20452-0.40(2.2361) \\
& d_{2}=-1.09895
\end{aligned}
$$

olarak bulunur. Daha sonra opsiyonun değerini de,

$$
\begin{aligned}
& V_{0}=\mathrm{PN}\left(\mathrm{d}_{1}\right)-\frac{\mathrm{X}}{\mathrm{e}^{\mathrm{r}_{f} t}} \mathrm{~N}\left(\mathrm{~d}_{2}\right) \\
& V_{0}=885.2 \mathrm{~N}(-0.20452)-\frac{2250}{\mathrm{e}^{(0.07)(5)}} \mathrm{N}(-1.09895) \\
& V_{0}=155.39 \text { birim }
\end{aligned}
$$

olarak buluruz. Reel opsiyon yaklaşımına göre projenin ikinci aşamasının değeri INA yaklaşımının aksine pozitif olmaktadır. Buna göre projenin toplam değeri:

NBD (toplam proje) $=$ NBD (birinci aşama) + alım opsiyonu değeri (ikinci aşama)

NBD (toplam proje $)=236.4$ birim +155.4 birim

$\mathrm{NBD}$ (toplam proje) $=391.8$ birim

olarak bulunur. Görüldüğü gibi indirgenmiş nakit akımları yaklaşımı belirsizliğin yüksek olduğu bir projenin değerini olduğundan daha düşük göstermektedir. Belirsizliğin yüksek olduğu riskli projelerde, yatırımın yapılması insiyatife bağlı ise, reel opsiyon yaklaşımı daha iyi sonuçlar vermektedir.

Yapulan analizlerin güçlendirilmesi için duyarlılık analizi yapılabilir. Duyarlılık analizi bir projenin değerini belirleyen değişken ve parametrelerin proje değerlendirmesi üzerindeki etkilerini inceler. Bu analiz yaplırken her değişken tek başına cle alınır ve diğer değişkenler sabit tutularak (ceteris paribus) sadece bir değiş̧enin proje değeri üzerindeki etkisini araştırılır (SARIASLAN, 1997: 230).

\section{Duyarlılık Analizi}

Örnek projede duyarlulk analizi iskonto oran ve proje aktiflerinin riskliliğine göre yaplabilir. Bu sayede, iskonto oranundaki ve risk seviyesindeki değişmelerin opsiyon değerini ve dolayısı ile proje değerini ne ölçüde ve ne yönde etkilediği saptanabilir. Tablo-5'te iskonto oranuna göre opsiyon yaklaşımı altında $\left(\mathrm{NBD}_{0}\right)$ ve INA yaklaşımı alında (NBDINA) göre projenin değerleri verilmiştir. INA yaklaşımına göre, 5. yldaki yatırım tutarının hem risksiz getiri oran üzerinden indirgenmesine göre $\left(\mathrm{NBD}_{\mathrm{Rf}}\right)$ hem de \%15 lik riske göre düzeltilmiş iskonto oranundan indirgenmesine göre (NBDINA) değerler gösterilmiştir. 
Tablo- 5 Iskonto Oranuna Göre Duyarlılık Analizi

\begin{tabular}{lrrrrr} 
Iskonto Oranı & $\% 10$ & $\% 15$ & $\% 20$ & $\% 25$ & $\% 30$ \\
\hline NBDiNA & 341,63 & 2,9 & $-191,13$ & $-301,02$ & $-361,60$ \\
NBD $_{\text {RF }}$ & 134,49 & $-482,68$ & $-891,12$ & $-1167,96$ & $-1359,83$ \\
NBD $_{0}$ & 805,22 & 391,78 & 159,80 & 23,98 & $-60,94$
\end{tabular}

Grafik- 1

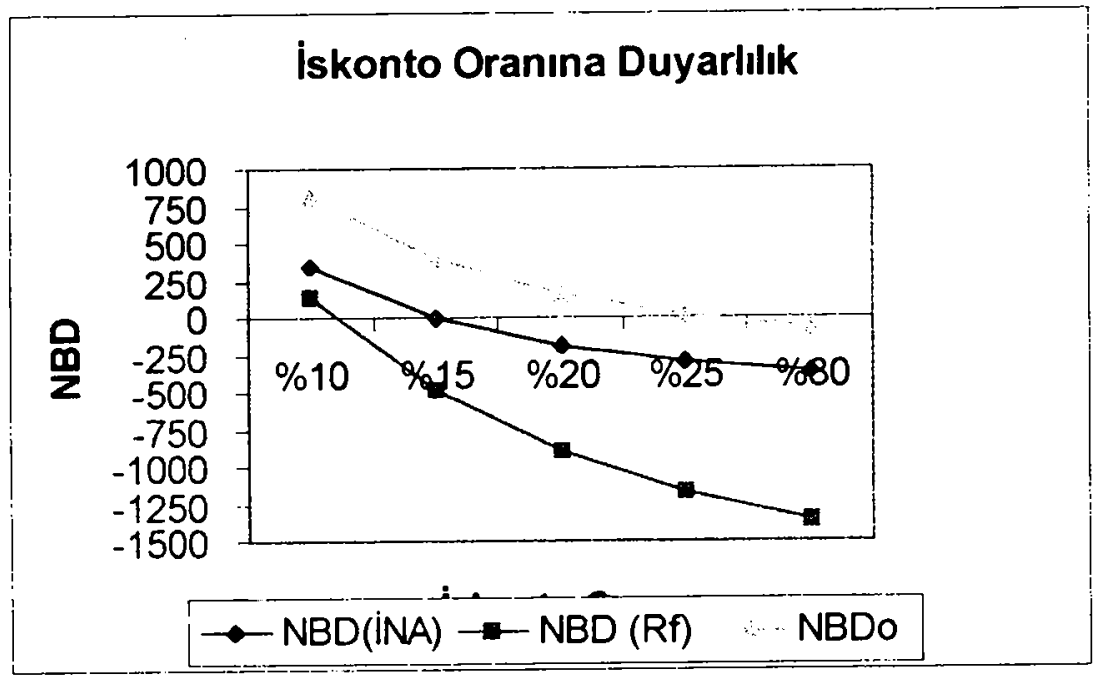

Tablo-5 ve Grafik-1'den de görüldüğü gibi opsiyon yaklaşımı altında projenin değeri iskonto oranundaki değişmelerden daha az etkilenmektedir. Ayrıca, projenin reddedilmesi de ancak iskonto oranı \%25'i geçtiği zaman sözkonusudur. Oysaki, INA yaklaşımı altında iskonto oranı \%10-15 civarında iken proje reddedilmektedir.

Şimdi de, proje aktiflerinin riskliliğini esas alarak duyarlılık analizi yapalım. Proje aktiflerinin riskliliği \%20 ile \%60 arasında değiştiğinde projenin 2. aşamasınun değerinin ve dolayısıyla projenin genel değerinin nasıl etkilendiği Tablo-6'da gösterilmiştir. Projenin 1. aşamasında INA yaklaşımı kullanıldığı için proje aktiflerinin riskliliği bu aşamayı etkilememektedir. 
Erkan Uysal • Yatırm Projeleri Analizinde Black-Scholes Opsiyon Fiyatlama Modelinin Kullanımı • 147

Tablo-6 Proje Aktlflerinin Riskliliğine Göre Duyarlllkk Analizi

\begin{tabular}{lrrrrr} 
Risk $(\sigma)$ & $\% 20$ & $\% 30$ & $\% 40$ & $\% 50$ & $\% 60$ \\
\hline NBD (2. Aşama) & 23,53 & 81,63 & 155,39 & 233,91 & 311,98 \\
NBD 0 & 259,92 & 318,02 & 391,78 & 470,30 & 548,37
\end{tabular}

Tablo-6 ve Grafik-2'de görüldüğü gibi proje aktiflerine ilişkin belirsizlik arttıkça, yani risklilik yükseldikçe opsiyon değerindeki artış nedeni ile projenin genel değerinde bir artış gözlenmektedir. Bu da finansal opsiyonları fiyatlama modelleri ile uyumlu bir sonuçtur.

Grafik-2

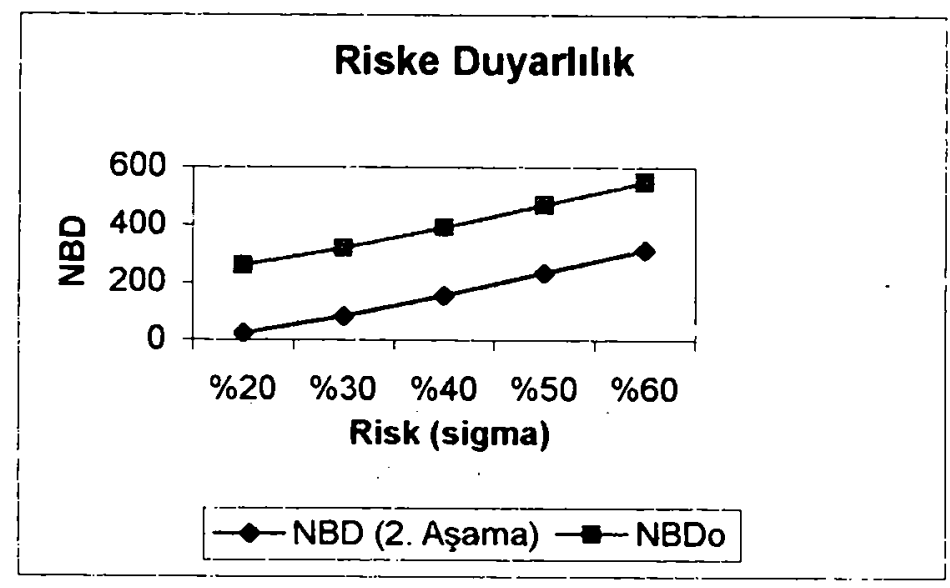

\section{Sonuç ve Değerlendirme}

Firmalar varlıkların devam ettirebilmek, piyasa değerlerini artırmak ve değişen koşullara uyum sağlamak için yatırım yapmak zorundadır. Bazı yatırım projeleri, yapıları itibari ile yüksek belirsizliğe sahiptir ve projenin ileri aşamalarında proje yapısın değiştirmek mümkündür. Bu gibi durumlarda firmalar ileri aşamalardaki yatırım harcamalarını yapıp yapmama opsiyonunu ellerinde bulundurur. Ileri aşamalardaki yatırım harcamasının yapulacağı zamana kadar geçen süre içinde projeyi çevreleyen şartlarda değişmeler olabilir. Firma değişen şartları gözönüne alarak projeyi yeniden gözden geçirip gerekli değişiklikleri yapabilir. Bu bakımdan yatırım harcamasını geciktirmek firmaya bir esneklik kazandırır Bu yapıdaki projelerin değerlendirilmesinde reel opsiyon 
yaklaşımı daha sağlıklı sonuçlar verir. Geleneksel INA yaklaşımı yatırım projelerinin değerini, opsiyonlan dikkate almadıklan için, olduğundan daha düşük göstererek projelerin reddine yol açar. Oysa ki, reel opsiyon yaklaşımı firsatları da dikkate alarak projenin değerini daha gerçekçi bir biçimde hesaplar.

Reel opsiyonların değerlendirilmesinde finansal opsiyonları fiyatlama modeli rahatlıkla kullanılabilir. Bu yaklaşımda, projenin değerini belirleyen değişkenler opsiyon fiyatlama modeli değişkenlerine uygun biçimde tanumlanarak proje değeri hesaplanur. Bu amaçla, Black-Scholes opsiyon fiyatlama modeli kullanulabilir. Yüksek belirsizliğe sahip ve zaman içinde projenin gidişatınu değiştirme imkan olan durumlarda yaturım projesi Black-Scholes opsiyon fiyatlama modelindeki beş değişken ile ifade edilebilir. Değişkenler tanımlandıktan sonra değerleri yerine konularak projenin gerçek değeri bulunabilir.

\section{Kaynakça}

BRIGHAM, Eugene F./GAPENSKI, Louis C. (1994), Financial Management: Theory and Practice (The Dryden Press-Harcourt Brace College Publishers).

DIXIT, A./PINDYCK, RS. (1994), Investment under (Incertainly (Princeton: Princeton University Press).

FRANCIS, J. Clark (1991), Investments: Analysis and Management (MCGraw Hill, 5. Edition).

HEMANTHA, S.B./CHAN. S. Park (1999). 'Economic Analysis of RED Projects: An Options Approach," Engineering Economist, 44/1 (Spring): 1-14.

KESTER, W.C. (1984). "Today's Optlons for Tomorrow's Growth," Harvard Business Review, March-Aprll: 153.160.

KROL, Karen (1998). "Keeping Options Open," Industry Week. 247/4: 22.

LUEHRMAN, Timothy A. (1998), "Investment Opportunities as Real Options: Getting Started on the Numbers," Haruard Business Review. July-August: 51-67.

LEVI, Maurice D. (1996), Intemational Finance, (McGraw Hill. $3^{\text {rd }}$ edition).

MORRIS, P.A./ TESBERG, E.O.MOLBE, A.L. (1991). "When Choosing RED Go With Long Shots,' Research-Technology Managemenh, January-February: 35.40.

MYERS, S.C. (1984), "Financlal Theory and Financial Strategy." Interfaces, 14/January-February: 126-137.

SARIASLAN. Halil (1997), Yaunm Projelerinin Hazrlanması ve Degerlendirilmesi, (Ankara: Tuthan Kitabevi, Genışletilmis 3. Baskı). 